\title{
Masked translation priming effects with low proficient bilinguals
}

\author{
Maria Dimitropoulou • Jon Andoni Duñabeitia • \\ Manuel Carreiras
}

Published online: 17 November 2010

(C) The Psychonomic Society 2010

\begin{abstract}
Non-cognate masked translation priming lexical decision studies with unbalanced bilinguals suggest that masked translation priming effects are asymmetric as a function of the translation direction (significant effects only in the dominant [L1] to nondominant [L2] language translation direction). However, in contrast to the predictions of most current accounts of masked translation priming effects, bidirectional effects have recently been reported with a group of low proficient bilinguals Duyck \& Warlop 2009 (Experimental Psychology 56:173-179). In a series of masked translation priming lexical decision experiments we examined whether the same pattern of effects would emerge with late and low proficient Greek (L1)-Spanish (L2) bilinguals. Contrary to the results obtained by Duyck and Warlop, and in line with the results found in most studies in the masked priming literature, significant translation priming effects emerged only when the bilinguals performed the task with L1 primes and L2 targets. The existence of the masked translation priming
\end{abstract}

M. Dimitropoulou $(\bowtie) \cdot J$. A. Duñabeitia $\cdot$ M. Carreiras Basque Center on Cognition, Brain and Language (BCBL), Paseo Mikeletegi 69,

20009 Donostia, Spain

e-mail: m.dimitropoulou@bcbl.eu

M. Dimitropoulou

University of La Laguna,

Tenerife, Spain

M. Carreiras

IKERBASQUE, Basque foundation for Science,

Bilbao, Spain

M. Carreiras

Departamento de Filología Vasca, University of the Basque

Country UPV/EHU,

Bilbao, Spain asymmetry with low proficient bilinguals suggests that crosslinguistic automatic lexico-semantic links may be established very early in the process of L2 acquisition. These findings could help to define models of bilingualism that consider L2 proficiency level to be a determining factor.

Keywords Masked translation priming - Bilingualism . Non-cognates $\cdot$ Cross-script

There is a general consensus across models of bilingual memory organization that concepts are represented within one common unified conceptual/semantic store (Potter, So, Von Eckardt, \& Feldman, 1984). However, the organization of the lexical representations belonging to the dominant (L1) and the nondominant (L2) languages and the way in which these interact with each other and with the semantic representations they map onto are issues under debate (see French \& Jacquet, 2004, for a review). An experimental paradigm that has been used repeatedly to address these issues is the masked priming paradigm (Forster \& Davis, 1984). In masked priming conditions, participants are unaware of the existence of the prime, but its influence can still be measured on target recognition time (see Kinoshita \& Lupker, 2003, for a review). In the present study, the masked priming paradigm was combined with the study of non-cognate translation equivalents (i.e., words from the two languages of a bilingual, sharing their meaning but not their form; e.g., $\beta \iota \beta \lambda i o$ and libro-Greek and Spanish for book) in a set of lexical decision experiments in order to examine the functionality of cross-language connections in low proficient bilinguals.

Previous masked translation priming lexical decision studies of bilinguals with relatively high proficiency in which non-cognate translations have been examined have 
repeatedly reported what is known as the masked translation priming asymmetry: consistent priming effects in the forward-translation direction (L1 primes and L2 targets), but elusive effects in the backward direction (L2 primes and L1 targets; e.g., De Groot \& Nas, 1991; Finkbeiner, Forster, Nicol, \& Nakamura, 2004; Gollan, Forster, \& Frost, 1997; Grainger \& Frenck-Mestre, 1998; Jiang, 1999 ${ }^{1}$; Jiang \& Forster, 2001; Kim \& Davis, 2003; Voga \& Grainger, 2007; Williams, 1994; see Duñabeitia, Perea, \& Carreiras, 2010a, for a review). However, it should be noted that this pattern of effects is restricted to studies using the lexical decision task (for cross-task differences, see Finkbeiner et al., 2004: Grainger \& Frenck-Mestre, 1998; Jiang \& Forster, 2001; Wang \& Forster, in press). More important for the purposes of the present study, this pattern of masked translation priming effects seems to vary also across different levels of L2 proficiency. Although the bilinguals who took part in the lexical decision studies reporting asymmetric masked translation priming effects were highly proficient, they were clearly not balanced bilinguals (i.e., they had a marked L1 preference) and were not simultaneous bilinguals, since they had acquired their L2 after their L1 during childhood or adolescence. This is an important point in the light of evidence obtained from two very recent masked translation priming lexical decision studies. In the first of these studies, Basnight-Brown and Altarriba, (2007) found forward- and backward masked translation priming effects of similar magnitude with a group of very highly proficient Spanish-English bilinguals (who reported even higher proficiency values for their L2 than for their L1). In the same line, (Duñabeitia, Dimitropoulou, UribeEtxebarria, Laka, \& Carreiras, 2010b) reported symmetric bidirectional masked translation priming effects, testing perfectly balanced simultaneous Spanish-Basque bilinguals. In fact, another group taken from the same Spanish-Basque bilingual population has recently yielded exactly the same pattern of effects in an ERP study.

The fact that the masked translation priming asymmetry obtained with unbalanced bilinguals vanishes only at very high levels of L2 competence is in line with the predictions of a number of models of bilingual memory organization. The revised hierarchical model (hereafter, RHM; Kroll \& Stewart, 1994; Kroll \& Tokowicz, 2001, 2005) proposes the existence of asymmetric links between the two translation directions. The RHM states that a bilingual has two language-specific lexicons and a common conceptual store (but see Kroll \& Dijkstra, 2002). Accordingly, L1 and L2

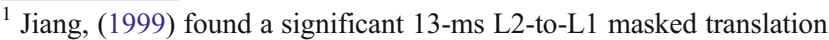
priming effect with Chinese-English bilinguals performing a lexical decision task (Experiment 1). However, this effect was not replicated in another four experiments reported in the same study.
}

translation equivalents are stored separately in the language-specific lexicons, but since they have the same semantic representation, they map onto the same conceptual node. However, at low levels of L2 proficiency, the RHM suggests that L2 words are only weakly connected to the shared conceptual node and that they therefore activate their corresponding concepts through the prior activation of their L1 translation equivalent. On the contrary, L1 words have strong direct connections to the conceptual level and weaker direct connections to their L2 translations. On the basis of this proposal, the RHM initially predicted that translation should be faster from L2 to L1 than from L1 to L2, due to the strong direct link of L2 words to their L1 translations (Kroll \& Stewart, 1994). However, and in light of the increasing masked translation priming evidence showing the opposite pattern of effects (priming effects only in the L1-to-L2 translation direction), the authors have proposed that only primes with strong connections to the conceptual level (e.g., L1 primes) can lead to masked translation priming effects (Kroll \& de Groot, 1997; Kroll \& Tokowicz, 2001). Consequently, the RHM predicts that early in the L2 acquisition process, L1 primes would be more likely than L2 primes to show masked translation priming effects (e.g., Kroll \& Tokowicz, 2001). At high levels of L2 proficiency, however, the model suggests that the strength of the connections between L1 and L2 words, as well as between L2 words and concepts, increases and that L2 words can gain direct access to the semantic level (e.g., Kroll \& Curley, 1988; Kroll, Michael, Tokowicz, \& Dufour, 2002; Talamas, Kroll, \& Dufour, 1999), leading to similar facilitative masked translation priming effects in both translation directions (Kroll \& Tokowicz, 2005). The extension of the RHM proposed by Duyck and Brysbaert, (2004, 2008), which assumes the activation of a single lexico-semantic translation route irrespectively of translation direction, also predicts an attenuation of the masked translation priming asymmetry at very high levels of L2 competence.

More recently, a number of models of bilingual lexico-semantic organization have been computationally implemented (e.g., BIA/BIA+, Dijkstra \& van Heuven, 2002, and Dijkstra, van Heuven, \& Grainger, 1998; BIMOLA, Léwy, Grosjean, Grosjean, Racine, \& Yersin, 2005; BSRN; DevLex; Zhao \& Li, 2006, and French, 1998; for reviews see Dijkstra, 2007; French \& Jacquet, 2004). Out of these, the DevLex and the bilingual interactive activation (hereafter, BIA and BIA+) models can effectively account for the masked translation priming asymmetry and its relation to the L2 proficiency level of the bilinguals, by assuming the existence of strong crosslanguage interactions. DevLex is a self-organizing neural network of bilingual processing based on co-occurrences (Hebbian learning) of phonological and semantic repre- 
sentations that become coactivated via associative links (see also Hernandez, Li, \& MacWhinney, 2005; Li \& Farkaš, 2002). This model assumes that for late and low proficiency learners of a second language, L2 words will be only diffusely stored and related in a "parasitic" way to L1 words (e.g., Hernandez et al., 2005). However, after extensive training, the L2 lexicon would be expanded, and a finer tuning of the semantic system would be achieved. From the basic principles of the Devlex model, it could be inferred that for late and low proficient L2 learners, the nodes corresponding to the briefly presented L2 primes will not be activated strongly enough (activation would be too diffuse) to cause the activation of their L1 translations, thus not leading to any priming ( $\mathrm{Li} \&$ Farkaš, 2002). However, it should be noted that the model does not make explicit predictions regarding masked translation priming effects, since it does not yet have translation equivalents in its simulated lexicon.

The BIA and BIA+ models (e.g., Dijkstra \& van Heuven, 1998, 2002; van Heuven, Dijkstra, \& Grainger, 1998), sharing their basic architecture with interactive activation models of monolingual visual word recognition (McClelland \& Rumelhart, 1981), account for the pattern of masked translation priming effects obtained across different levels of L2 proficiency in terms of frequency and recency of use of L1 and L2 words. That is, for unbalanced bilinguals, it is proposed that L2 words have lower resting levels of activation, due to the fact that, on average, they are encountered less often than L1 words. As a consequence, L2 words need more activation to surpass their activation threshold, and therefore, their recognition process is slower than that of L1 words. Under brief masked presentation (short stimulus onset asynchronies), considering the slower access to L2, no (or little) priming on the L1 target word is expected. On the contrary, at the highest levels of L2 proficiency, and especially when L2 acquisition is simultaneous with that of L1, the resting levels of L2 words will be almost as high as those of L1 words, and their recognition will take place equally efficiently. Correspondingly, for balanced and simultaneous bilinguals, the brief presentation of an L2 prime would be expected to facilitate its following L1 translation equivalent as much as would be expected for the opposite priming direction (i.e., L1 to L2; see Duñabeitia et al., 2010a, for supporting evidence).

Overall, this brief review of the masked translation priming literature suggests that the initially reported masked translation priming asymmetry is attenuated with increased L2 proficiency, in line with the predictions made by the above-mentioned models. Considering this pattern of results, a similar asymmetric pattern in groups of low proficiency L2 learners could be expected. However, in the only study so far examining masked translation priming effects in a lexical decision task with low proficiency bilinguals, Duyck and Warlop, (2009) obtained a very different pattern of results. The authors tested a group of 24 Dutch-French bilinguals who started learning French after the age of 11 and reported, on average, a low proficiency level in that language (3.9 on a scale from 1 to 7 , with higher values representing better linguistic competence). Interestingly, they found significant priming effects in both translation directions (48 and $26 \mathrm{~ms}$ in forward and backward translation, respectively) that were not statistically different from each other, despite their large numerical difference. The authors argued that these results provided evidence of a lack of a qualitative difference in the lexico-semantic architecture of the dominant and the nondominant languages and of direct conceptual access to L2 words, even at early stages of L2 acquisition (in line with Duyck \& Brysbaert, 2004, 2008; see also Schoonbaert, Duyck, Brysbaert, \& Hartsuiker, 2009). This pattern of effects obtained with late and low proficiency bilinguals can be considered as unexpectedfirst, due to the lack of an asymmetry across the two translation directions, and second, due to the significant L2-to-L1 translation effect. On the basis of the magnitude difference of the effects $(22 \mathrm{~ms})$, one could argue that they are clearly not symmetric. However, the apparent absence of an interaction between target language and prime language $(p>.11)$ indicates that the expected asymmetry is not present. (Note, however, that this lack of asymmetry could have been caused by a lack of statistical power, since only 24 participants completed the experiment.) This pattern is not predicted by most of the current models of bilingual lexico-semantic organization, which propose that at early stages of L2 acquisition, the asymmetry would be found (e.g., RHM, BIA, BIA+, DevLex). Moreover, and in line with what the models predict, so far only studies testing bilinguals at the highest levels of L2 competence have obtained symmetric effects across the two translation directions (Basnight-Brown \& Altarriba, 2007; Duñabeitia et al., 2010b; Duñabeitia et al., 2010a). Bilinguals with a medium or a relatively high level of L2 proficiency have typically shown the masked translation priming asymmetry, in both behavioral and ERP studies (e.g., Gollan et al., 1997; Jiang, 1999; Midgley, Holcomb, \& Grainger, 2009; Schoonbaert et al., 2009). This discrepancy between most preceding evidence and the findings by Duyck and Warlop suggests that it would be prudent to take another look at this issue and to further examine exactly how a low level of L2 proficiency affects masked translation priming effects. Readdressing this issue would help to identify whether interlingual lexico-semantic connections are active and functional at low levels of L2 proficiency and would offer a better understanding of 
how these links are established in the process of L2 acquisition.

In order to address these issues, in the present study, a group of late and low proficiency Greek (L1)-Spanish (L2) bilinguals was tested in a cross-script masked translation priming lexical decision task (for further evidence of crossscript masked translation priming with high proficiency bilinguals, see also Finkbeiner et al., 2004; Gollan et al., 1997; Jiang, 1999; Jiang \& Forster, 2001; Kim \& Davis, 2003). The same group of bilinguals performed lexical decisions on Spanish (L2; Experiment 1a) and Greek (L1; Experiment $1 \mathrm{~b}$ ) target words preceded by their non-cognate translation equivalents (see also Voga \& Grainger, 2007, for further evidence with the same Greek-Roman script combination). The same experimental group was used to study both translation directions in order to achieve an accurate measure of the magnitude of the observed effects while minimizing possible variability due to individual differences. Furthermore, several priming conditions were included in both experiments for control purposes. These consisted of two unrelated priming conditions with words in the two languages concerned (for which we expected null priming effects) and a within-language repetition condition. The latter condition was included in order to compare any possible translation priming effects against a condition that has repeatedly been shown to lead to robust masked priming effects (e.g., Forster \& Davis, 1984; Misra \& Holcomb, 2003; Perea \& Rosa, 2000). The aim of comparing each related condition (identity and translation) with its corresponding baseline was to uncover language-related and language-independent processes. Moreover, the inclusion of these control conditions allowed for the creation of perfectly balanced experimental lists, with half of the primes belonging to one of the languages and the other half to the other. This way, no processing advantage was provided to one of the languages of the participants (see Altarriba \& BasnightBrown, 2007). This $2 \times 2$ fully crossed experimental design has previously been applied in the study of masked translation priming effects with bilingual samples (Duñabeitia et al., 2010b; Midgley et al., 2009; Perea, Duñabeitia, \& Carreiras, 2008).

Taking into account theoretical proposals, as well as previous evidence with high proficiency bilinguals, no backward translation priming would be expected in the present population, given the clear L1 dominance. However, the appearance or not of the facilitative effect typically reported in the forward-translation direction with bilinguals of higher levels of L2 proficiency is unpredictable, in the sense that it is unknown whether the links on which the translation process relies will have become functional in the case of bilinguals with limited L2 exposure (but see Duyck \& Warlop, 2009).

\section{Experiments 1a and 1b}

Method

Participants The same group of Greek-Spanish bilinguals completed Experiments $1 \mathrm{a}$ and $1 \mathrm{~b}$. Forty-two native Greek speakers (mean age, 25.0 \pm 3.4 years), students of Spanish in Athens, with normal or corrected-to-normal vision, participated voluntarily in these experiments. All the participants had lived only in Greece and were either in the process of acquiring or had recently acquired their college degree (mean years of formal education, $16.1 \pm 0.9$ years). They were late learners of Spanish and had an overall low level of proficiency in that language. In order to test their degree of exposure and level of proficiency in Spanish, all of them completed a Greek version of the Language Experience and Proficiency Questionnaire (LEAP-Q; Marian, Blumenfeld, \& Kaushanskaya, 2007). According to their answers, all of them had started learning Spanish as adults (mean age, 22.3 \pm 3.4 years) and had been receiving Spanish lessons for around 3 years $(M=2.8 \pm 0.8)$. Their mean level of Spanish proficiency, as calculated by their self-ratings, was of $5.4( \pm 1.5)$ on a 0 -to-10 scale (10 representing the highest level of proficiency; for further information regarding the level of proficiency of the participants and their degree of exposure to Spanish, see Table 1). None of them was exposed to the Spanish language in any context (family, professional, etc.) other than the language school in which they were receiving classes at the moment of the testing. Finally, 28 out of 42 participants reported also having knowledge of English. All the participants were living in Greece at the time of testing (L1 environment).

Materials For Experiment 1a, we selected 56 Spanish words as targets, taken from the Spanish LEXESP database (Sebastián-Gallés, Martí, Carreiras, \& Cuetos, 2000). These words had a mean frequency of 96.75 occurrences per million (range, 7-391) and a mean number of 5.34 letters (range 3-10; Davis \& Perea, 2005). These targets were presented in uppercase and were preceded by lowercase primes that were (1) the same as the target (identity condition, e.g., salud-SALUD; the Spanish for health), (2) the Greek non-cognate unique translation of

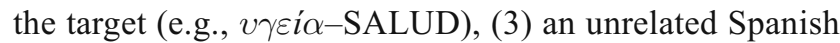
word (e.g., fuego-SALUD; fuego is the Spanish for fire), or (4) am unrelated Greek word (e.g., $\varepsilon \pi \alpha \phi \eta^{\prime}-$ SALUD; $\varepsilon \pi \alpha \phi \dot{\eta}$ is the Greek for contact). The Greek primes in the translation condition were selected from the GreekLex database (Ktori, van Heuven, \& Pitchford, 2008) and had a mean frequency of 47.5 appearances per million (range, 1-290) and a mean number of 6.23 letters (range, 4-11). Two external judges with an excellent competence 
Table 1 Mean of Spanish (L2) proficiency in Experiments 1a and 1b according to the Language Experience and Proficiency Questionnaire (LEAP-Q). Standard deviations are provided within parentheses

\begin{tabular}{ll}
\hline Age of first exposure & $22.3(3.4)$ \\
Years of exposure & $2.8(0.8)$ \\
Hours of exposure per week & $5.0(1.8)$ \\
Level of exposure (scale 0 to 10)* & $4.5(2.9)$ \\
Percentage of time of exposure & $12(8.2)$ \\
General level of proficiency (scale 0 to 10$)^{* *}$ & $5.4(1.5)$ \\
\hline
\end{tabular}

$* 0=$ never, $10=$ always; $* * 0=$ low proficiency, $10=$ high proficiency

in the two languages confirmed that the Greek words selected as translations for the Spanish words were, in fact, the only (or most common) translations. The primes of the within-language unrelated condition were matched as closely as possible to the target words in both frequency and number of letters and the Greek primes in the between-language unrelated condition were matched to the related Greek primes (see Table 2; see the Appendix for a full listing of the word materials used). An additional set of 56 orthographically legal nonwords in Spanish (e.g., CÉDEMO) was also created. None of the nonwords was an actual word in Greek, and they were preceded by either Greek or Spanish prime words, matched in length and frequency to the primes of the word trials.

In Experiment $1 \mathrm{~b}$, the 56 target words used were the Greek translations of the Spanish targets used in Experiment 1a. These targets were preceded by primes in the same conditions as those in Experiment 1a (see Table 2 and the Appendix). In relation to the targets, the primes were (1) the same as the target (identity

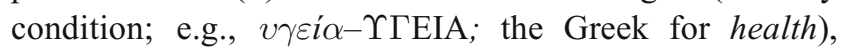
(2) the Spanish non-ognate unique translation of the target (e.g., salud-ҮГЕIA), (3) an unrelated word in Greek (e.g., $\varepsilon \pi \alpha \phi \dot{\eta}-\Upsilon \Gamma Е I A ; \varepsilon \pi \alpha \phi \dot{\eta}$ is the Greek word for contact), or

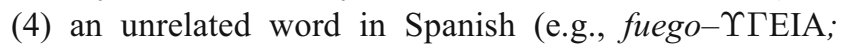
fuego is the Spanish word for fire). An additional set of 56 orthographically legal nonwords in Greek (e.g., ZE $\Lambda \Lambda \mathrm{H}$ ) was also created for the purposes of the lexical decision. None of the nonwords was an actual word in Spanish, and all of them were preceded by the same set of Greek and
Spanish primes as were the nonwords in Experiment 1a. Four lists of materials were constructed for each subexperiment ( $1 \mathrm{a}$ and $1 \mathrm{~b}$ ), so that each target appeared only once in each list but, each time, in a different priming condition. Different participants were randomly assigned to each of the lists.

Procedure Participants completed the two subexperiments (1a and $1 \mathrm{~b})$ in two experimental sessions, with at least a 3-day gap between them. The order of the sessions was counterbalanced across participants. Both sessions were held individually in a quiet room. Stimuli presentation and recording of response times were controlled by a PC. The experiments were run using DMDX (Forster \& Forster, 2003). Reaction times were measured from target onset until a response was given or for a maximum of 2,500 ms. On each trial, a forward mask consisting of a row of hash marks (\#) was presented for $500 \mathrm{~ms}$. The length of the row of hash marks was defined on a trial-level basis, keeping it the same as the length of the longest string (prime or target). Next, the prime was presented in lowercase and stayed on the screen for $50 \mathrm{~ms}$ (three cycles; each cycle corresponding to $16.6 \mathrm{~ms}$ on the CRT monitor). The prime was immediately followed by the presentation of the target stimulus in uppercase. Masks, primes, and targets were presented in the center of the screen. The target remained on the screen until the participants responded or for a maximum of 2,500 ms. Participants were instructed to press, as quickly and accurately as possible, one of two buttons on the keyboard to indicate whether the uppercase letter string was a legitimate word or not in the test language. They were not informed of the presence of lowercase items, and none of them reported (after the experiment) conscious knowledge of the existence of any prime. Trial presentation was randomized across participants. In each experimental session, each participant received a total of 12 practice trials (six words and six nonwords) prior to the 112 experimental trials. In Experiment 1a, the instructions (and the interactions with the participants) were given in Spanish, and in Experiment 1b, in Greek. Each experimental session lasted approximately $14 \mathrm{~min}$.
Table 2 Mean word frequency (per million) and length (in number of letters) of the prime-TARGET word pairs

\begin{tabular}{|c|c|c|c|c|c|c|}
\hline & \multicolumn{4}{|l|}{ Primes } & & \\
\hline & \multicolumn{2}{|l|}{ Spanish } & \multicolumn{2}{|l|}{ Greek } & \multicolumn{2}{|l|}{ Targets } \\
\hline & Repetition & Unrelated & Repetition & Unrelated & Spanish & Greek \\
\hline Frequency & 96.8 & 96.9 & 47.5 & 47.4 & 96.8 & 47.5 \\
\hline Length & 5.3 & 5.4 & 6.2 & 6.2 & 5.3 & 6.2 \\
\hline
\end{tabular}


Results and discussion

Two of the participants were discarded after completing both sessions, since they reported in the offline language proficiency questionnaire having spent relatively long periods in Spain in the recent past. Thus, analyses were performed on the data collected from the remaining 40. Mean latencies for correct responses and error rates are presented in Table 3. ANOVAs based on participant and item response latencies and error percentages were conducted on the basis of a 2 (relatedness: related, unrelated) $\times 2$ (orime language: Spanish, Greek) $\times 4$ (ist: 1,2,3, or 4) design. The list factor was included as a dummy variable (Pollatsek \& Well, 1995).

\section{Experiment 1a: Spanish targets}

ANOVAs on the reaction times revealed a main effect of relatedness: Target words preceded by their Spanish repetition or Greek translation were responded to faster $(46 \mathrm{~ms})$ than words preceded by unrelated primes, $F_{1}(1,36)$ $=43.21, M S E=1,929, p<.001 ; F_{2}(1,52)=31.67, M S E=$ $3,597, p<.001$. The main effect of prime language was also significant, with targets preceded by a Spanish prime being responded to faster (29 ms faster) than those preceded by a Greek prime, $F_{1}(1,36)=19.62, M S E=1,662, p<.001$; $F_{2}(1,52)=14.15, M S E=3,300, p<.001$. The interaction between the two factors was significant $\mathrm{F} 1(1,36)=5.93$, $\mathrm{MSE}=1,794, p<.05 ; \mathrm{F} 2(1,52)=8.19, \mathrm{MSE}=2,786, p<$ .01 , showing that the repetition and the translation priming effects significantly differed in magnitude from each other $(62$ and $29 \mathrm{~ms}$, respectively). Planned pairwise comparisons showed that both effects were significant (repetition, $F_{1}(1$, $36)=39.51, M S E=1,943, p<.001 ; F_{2}(1,52)=37.49$, $M S E=3,183, p<.001 ;$ translation, $F_{1}(1,36)=9.67, M S E=$ $\left.1,780, p<.01 ; F_{2}(1,52)=5.43, M S E=3,200, p<.05\right)^{2}$.

ANOVAs on the error data revealed a main effect of prime language, with target words preceded by Greek

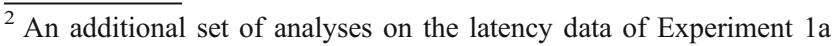
was performed removing the words that were perfect cognates of English words (i.e., words with complete formal overlap in two languages - the words color and hotel; see also Duyck \& Warlop, 2009 , for a similar analysis). This was done in order to discard any potential mediation of the knowledge of English reported by some of our participants. Such coexistence of a third language is a commonly seen fact in bilingual research (e.g., Christoffels, Firk, \& Schiller, 2007; Duyck \& Warlop, 2009). The results of these analyses showed that the translation priming effect was virtually unaffected by the inclusion of these Spanish-English cognates in the experimental lists (both $p \mathrm{~s}<.05$ ), suggesting that the Greek-to-Spanish translation priming effect we obtained was not mediated by a coactivation of the English translation of the test items. The authors want to thank W. Duyck and an anonymous reviewer for pointing this out.
}

primes (both related and unrelated) being more accurately recognized $(2.4 \%$ fewer errors) than were those preceded by related and unrelated Spanish primes, $F_{1}(1,36)=6.44$, $M S E=36, p<.05 ; F_{2}(1,52)=7.25, M S E=45, p<.05$. No other effects on the error rate analysis were significant, all $p \mathrm{~s}>.11$.

\section{Experiment 1b: Greek targets}

ANOVAs on the reaction times revealed a main effect of relatedness: Greek target words preceded by their Greek repetitions or by their Spanish translations were responded to faster $(21 \mathrm{~ms}$ faster) than were those preceded by unrelated words, $F_{1}(1,36)=9.62, M S E=1,848, p<.01$; $F_{2}(1,52)=7.25, M S E=3,075, p<.01$. The main effect of prime language was also significant, with targets preceded by Greek primes responded to $27 \mathrm{~ms}$ faster than were those preceded by Spanish primes, $F_{1}(1,36)=9.54, M S E=$ $3,009, p<.01 ; F_{2}(1,52)=12.97, M S E=2,686, p<.01$. Given the significant interaction between the two factors, pairwise comparisons were conducted, $F_{1}(1,36)=13.92$, $M S E=2,010, p<.01 ; F_{2}(1,52)=10.07, M S E=3,938, p<$ .01 . Participants responded $47 \mathrm{~ms}$ faster when the primes were identical repetitions of the targets than when the primes were unrelated words, $F_{1}(1,36)=33.30, M S E=1,357$, $p<.001 ; F_{2}(1,52)=19.84, M S E=3,061, p<.001$. On the contrary, when the targets were preceded by their Spanish translations, there was no significant difference, as compared with when they were preceded by Spanish unrelated words (a nonsignificant 5-ms difference, both $p$ s $>.58$ ).

ANOVAs on the error data showed a significant effect of relatedness, which was marginally significant in the analysis by items, $F_{1}(1,36)=4.35, M S E=11, p<.05$; $F_{2}(1,52)=3.48, M S E=18, p>.07$. This effect indicated that participants responded more accurately $(2.4 \%$ fewer errors) when targets were preceded by related primes (either in Greek or in Spanish) than when they were preceded by unrelated primes of both languages. The rest of the effects were not significant (all $p \mathrm{~s}>.51$ ).

The main finding of Experiment 1 (1a and 1b) was a clear asymmetric pattern of masked translation priming effects with late and low proficient Greek-Spanish bilinguals. On the one hand, when primes were the Greek (L1) non-cognate translations of the Spanish (L2)

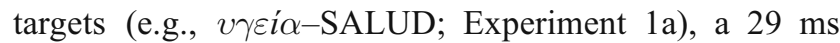
significant facilitative effect emerged. On the other hand, when the language order was reversed (i.e., L2 primes $-\mathrm{L} 1$ targets, e.g., salud- $Г$ ГEIA; Experiment 1b), no translation priming was obtained. The null translation priming effect found in Experiment $1 \mathrm{~b}$ cannot be attributed to a lack of effective processing of L2 primes, since there was a significant within-language repetition priming effect for L2 words, which did not differ in magnitude to that found 
Table 3 Mean lexical decision times (RTs, in Milliseconds) and error rates $(\% \mathrm{E})$ for word targets in Experiments $1 \mathrm{a}$ and $1 \mathrm{~b}$. Repetition priming was measured as the difference between the target repetition and the same language unrelated priming conditions, while translation priming was measured as the difference between the across languages repetition and across languages unrelated priming conditions

\begin{tabular}{|c|c|c|c|c|c|c|c|c|c|c|c|c|}
\hline \multirow[t]{4}{*}{ Targets } & \multicolumn{8}{|c|}{ Priming Condition } & & & & \\
\hline & \multicolumn{4}{|c|}{ Spanish (L2) } & \multicolumn{4}{|c|}{ Greek (L1) } & \multicolumn{4}{|c|}{ Priming Effect } \\
\hline & \multicolumn{2}{|c|}{ Repetition } & \multicolumn{2}{|c|}{ Unrelated } & \multicolumn{2}{|c|}{ Repetition } & \multicolumn{2}{|c|}{ Unrelated } & \multicolumn{2}{|c|}{ Repetition } & \multicolumn{2}{|c|}{ Translation } \\
\hline & $R T$ & $\% E$ & $R T$ & $\% E$ & $R T$ & $\% E$ & $R T$ & $\% E$ & $R T$ & $\% E$ & $R T$ & $\% E$ \\
\hline Spanish (L2) & 703 & 6.1 & 765 & 8.0 & 748 & 3.9 & 777 & 5.4 & 62 & 1.9 & 29 & 1.5 \\
\hline Greek (L1) & 720 & 1.3 & 715 & 2.1 & 667 & 1.1 & 714 & 2.3 & 47 & 1.2 & -5 & 0.8 \\
\hline
\end{tabular}

Note: Mean reaction time and mean error rate for nonwords was $944 \mathrm{~ms}$ and 10.2\%, respectively, in Experiment $1 \mathrm{a}$ and $902 \mathrm{~ms}$ and $5.2 \%$, respectively, in Experiment $1 \mathrm{~b}$

in Experiment 1a for L1 words (62 and $47 \mathrm{~ms}$ in Experiments 1a and $1 \mathrm{~b}$, respectively). It should also be noted that consistent code-switching effects emerged in both language directions: higher processing costs in all the between-language conditions (related and unrelated) than in the within-language conditions (29 and $27 \mathrm{~ms}$ in Experiments $1 \mathrm{a}$ and $1 \mathrm{~b}$, respectively; see Chauncey, Grainger, \& Holcomb, 2008; von Studnitz \& Green, 1997).

The pattern of results obtained from the separate analyses of Experiments $1 \mathrm{a}$ and $1 \mathrm{~b}$ was further confirmed by a post hoc combined analysis considering Target language as a factor. This analysis corroborated the asymmetric pattern of the masked translation priming effects by showing a significant interaction of target language and relatedness in the between-language priming conditions, $\left(F_{1}(1,36)=4.79, M S E=2,514, p<.05 ; F_{2}(1\right.$, $52)=3.98, M S E=3,507, p=.05)$. In contrast, the magnitude difference between the two within-language repetition priming effects (Spanish and Greek targets) was not significant (both $p \mathrm{~s}>.21$ ), ensuring that there was an efficient processing of both L1 and L2 primes. Thus, the persistence of the asymmetric masked translation priming effect with the present group of bilinguals, who had only limited and very recent exposure to L2, provides evidence for the existence of active and functional interlingual connections even at early stages of L2 acquisition (e.g., Duyck \& Brysbaert, 2004; Schoonbaert et al., 2009). Furthermore, we also found an overall cost associated with the low level of knowledge in Spanish of our bilinguals: Participants took more time $(44 \mathrm{~ms})$ and made more errors (4.1\%) when responding to Spanish targets, all $p$ s $<.05$.

The pattern of effects obtained in Experiments $1 \mathrm{a}$ and $1 \mathrm{~b}$ fully replicate previous evidence from bilinguals with a higher level of L2 linguistic competence and suggest that the interlingual connections are active and functional even when L2 has been recently acquired and when the proficiency level is remarkably low. Crucially, our results are in clear contrast to those recently reported by Duyck and Warlop, (2009) in the only study that has so far examined masked translation priming effects at low levels of L2 proficiency.

An additional Spanish monolingual group was tested with exactly the same materials as those in Experiment 1a (Spanish targets). With this control experiment, we expected to identify any potential influence of lower level features across our materials (e.g., visual overlap), or any other uncontrolled factor that could have led to the facilitation effects in the between-language related condition from Experiment 1a (i.e., the masked translation priming effect). The only possible effect to be expected would be within-language repetition priming (e.g., salud-SALUD), considering the null knowledge of Greek of this test sample. Furthermore, a cost related to the change of script was also expected for those targets preceded by Greek primes, since this group had no previous exposure to the Greek script. Such an effect would be somewhat analogous to the code switching effects obtained with our bilingual group.

\section{Experiment 2: Spanish monolingual group}

\section{Method}

Participants Thirty-two undergraduates from the University of La Laguna (Spain) completed this experiment for course credit. All participants were native Spanish monolinguals and had no previous exposure to Greek.

Materials The same set of materials as that in Experiments la was used.

Procedure The procedure followed was exactly the same as that in Experiment 1a. 
Table 4 Mean lexical decision times (in ms, RT) and error rates (\%E) for word targets in Experiment 2

Priming Condition

\begin{tabular}{|c|c|c|c|c|c|c|c|c|c|c|c|}
\hline \multicolumn{4}{|c|}{ Spanish (L1) } & \multicolumn{4}{|c|}{ Greek } & \multicolumn{4}{|c|}{ Priming Effect } \\
\hline \multicolumn{2}{|c|}{ Repetition } & \multicolumn{2}{|c|}{ Unrelated } & \multicolumn{2}{|c|}{ Repetition } & \multicolumn{2}{|c|}{ Unrelated } & \multicolumn{2}{|c|}{ Repetition } & \multicolumn{2}{|c|}{ Translation } \\
\hline$R T$ & $\% E$ & $R T$ & $\% E$ & $R T$ & $\% E$ & $R T$ & $\% E$ & $R T$ & $\% E$ & $R T$ & $\% E$ \\
\hline 591 & 1.1 & 633 & 2.7 & 644 & 2.9 & 650 & 2.9 & 42 & 1.6 & 6 & 0 \\
\hline
\end{tabular}

Note: Mean reaction time and mean error rate for nonwords were $711 \mathrm{~ms}$ and $3 \%$, respectively

Results and discussion

Mean latencies for correct responses and error rates are presented in Table 4. Since the design was exactly the same as that for the previous experiment, the same analyses were performed.

ANOVAs on the reaction times revealed a main effect of relatedness: Target words preceded by their repetition (in either Spanish or Greek) were responded to faster (23 ms faster) than were those preceded by an unrelated word, $F_{1}(1$, $28)=10.11, M S E=1,710, p<.01 ; F_{2}(1,52)=11.10$, $M S E=2,894, p<.01$. Besides, a main effect of prime language was also significant, with targets preceded by Spanish primes responded to faster (35 ms faster) than those preceded by Greek primes, $F_{1}(1,28)=37.73, M S E=1,064$, $p<.001 ; F_{2}(1,52)=25.96, M S E=2,521, p<.001$. Importantly, the interaction between the two factors was significant, $F_{1}(1,28)=14.15, M S E=722, p<.001 ; F_{2}(1$, $52)=7.05, M S E=3,192, p<.05$. When primes were identical repetitions of the targets (within-language repetitions), participants responded $42 \mathrm{~ms}$ faster, as compared with when primes were unrelated Spanish words, $F_{1}(1,28)=$ $28.38, M S E=953, p<.001 ; F_{2}(1,52)=13.48, M S E=$ $4,020, p<.01$. On the contrary, when targets were preceded by their Greek translations there was no significant difference, as compared with when they were preceded by Greek unrelated words (a nonsignificant $6 \mathrm{~ms}$ difference, both $p \mathrm{~s}>.55$ ).

ANOVAs on the error data did not reveal any significant effects (all $p \mathrm{~s}>.14$ ).

As was expected, the only significant effect obtained with the Spanish monolingual group was the withinlanguage repetition priming effect (i.e., Spanish words preceded by identical primes). Besides, there was a significant cost associated with the language and script switch, for those Spanish target words preceded by (related or unrelated) Greek masked primes. The findings of this monolingual control experiment confirmed that the forward masked translation priming effect of Experiment 1a was not the result of potentially uncontrolled variables or of any specific properties of the test materials used.

The most important finding of the experiments reported so far is the asymmetric pattern of masked translation priming effects obtained with a group of late and low proficiency Greek-Spanish bilinguals, with a facilitative translation priming effect emerging only when Spanish (L2) targets were preceded by their Greek (L1) non-cognate translation equivalents. This pattern of masked translation priming effects is consistent with previous masked translation priming studies testing bilinguals relatively high in proficiency and with the predictions of most models of bilingual lexico-semantic organization. However, this pattern sharply contrasts with the findings reported by Duyck and Warlop, (2009) in the only study examining these effects with low proficient bilinguals.

Before discussing theoretical hypotheses that could account for the discrepancy between the present results and those obtained by Duyck and Warlop, (2009), several critical differences in the methodology that was followed in each study should be mentioned. The present experiments followed the conventional masked priming procedure, consisting of the presentation of the forward mask for $500 \mathrm{~ms}$, followed by the presentation of the prime for $50 \mathrm{~ms}$, and immediately followed by the target (see also Duñabeitia et al., 2010; Finkbeiner et al., 2004; Gollan et al., 1997; Jiang, 1999, Experiments 1 and 2; Jiang \& Forster, 2001, Experiments 3 and 4; Voga \& Grainger, 2007; Wang \& Forster, in press, Experiment 3). However, Duyck and Warlop used a noncanonical version of the masked priming paradigm, including some changes that merit attention ${ }^{3}$. The authors presented the forward mask only for $56 \mathrm{~ms}$, and they interpolated a 56-ms backward mask between the prime (presented for $56 \mathrm{~ms}$ ) and the target. Such a brief presentation of the forward mask is not usually found in the masked priming literature. Moreover, it could be argued that such a brief presentation of the forward mask could have enhanced prime visibility. With regard to the use of a 56-ms backward mask, one might argue that it could add processing time to the primes, facilitating their effective activation (see DelCul, Baillet, \& Dehaene, 2007, for a discussion on how different SOAs might affect prime processing). This way, participants could

\footnotetext{
${ }^{3}$ The authors want to thank Prof. Kenneth Forster for pointing this out.
} 
have had enough time to access L2 words, leading to similar masked translation priming effects in both translation directions. Still, evidence so far has not been conclusive on whether the inclusion of a backward mask modulates the pattern of masked translation priming effects obtained in the lexical decision task. Some studies using a backward mask have shown significant L2-to-L1 masked translation priming effects (e.g., Basnight-Brown \& Altarriba, 2007; Schoonbaert et al., 2009), whereas others have not shown this effect (e.g., Finkbeiner et al., 2004; Jiang, 1999, Experiments 4 and 5; Jiang \& Forster, 2001).

In order to provide more conclusive evidence regarding the reasons leading to the observed discrepancy between the present results and those obtained by Duyck and Warlop, (2009) and to clearly identify the pattern of masked translation priming effects obtained at early stages of L2 acquisition, another set of cross-script masked translation priming lexical decision experiments was carried out. In Experiments $3 \mathrm{a}$ and $3 \mathrm{~b}$ we examined the potential influence of the somewhat unusual timing and sequence of masked priming events used by Duyck and Warlop. A different group of late and low proficiency Greek-Spanish bilinguals was presented with the same set of materials as that used in Experiments $1 \mathrm{a}$ and $1 \mathrm{~b}$. However, following the procedure of Ducyk and Warlop, the forward mask was presented for only $50 \mathrm{~ms}$, and an additional 50-ms backward mask was interpolated between the prime and the target. If our results replicate those of Experiments $1 \mathrm{a}$ and $1 \mathrm{~b}$ - that is, if a significant masked translation priming effect is obtained only with Greek (L1) primes and Spanish (L2) targets-this would suggest that the masked translation priming effect reported by Duyck and Warlop for low proficient bilinguals is due to something other than the additional processing time provided to the prime by the inclusion of a backward mask (see also Jiang, 1999). If, on the contrary, symmetrical and bidirectional masked translation priming effects are obtained in both translation directions, this would suggest that when participants have more time to process the primes, the otherwise elusive backward masked translation priming effect emerges even at low levels of L2 proficiency.

\section{Experiments 3a and $\mathbf{3 b}$}

Method

Participants A different group of Greek-Spanish bilinguals, matched as closely as possible to the group who took part in Experiments 1a and 1b, completed Experiments $3 \mathrm{a}$ and $3 \mathrm{~b}$. Forty-four native Greek speakers
Table 5 Mean of Spanish (L2) proficiency in Experiments 3a and 3b according to the Language Experience and Proficiency Questionnaire (LEAP-Q). Standard deviations are provided within parentheses

\begin{tabular}{ll}
\hline Age of first exposure & $23.2(5.1)$ \\
Years of exposure & $2.8(1.0)$ \\
Hours of exposure per week & $5.5(2.0)$ \\
Level of exposure (scale 0 to 10)* & $3.8(1.7)$ \\
Percentage of time of exposure & $10.4(6.8)$ \\
General level of proficiency (scale 0 to 10$)^{* *}$ & $5.3(1.5)$ \\
\hline
\end{tabular}

$* 0=$ never, $10=$ always $* * 0=$ low proficiency, $10=$ high proficiency

(mean age, $26.1 \pm 5.0$ years) with normal or corrected-tonormal vision participated voluntarily in these experiments. Participants reported either having completed college studies or being at the process of acquiring their college degree (mean years of formal education, $15.2 \pm 1.7$ years). Just as in Experiment 1, 35 participants (out of 44) also reported having some knowledge of English. All the participants were learning Spanish at the Instituto Cervantes of Athens and were living in Greece at the time of testing (L1 environment). All the participants completed the same questionnaire as the participants in Experiments $1 \mathrm{a}$ and $1 \mathrm{~b}$. According to their answers, they were all late learners of Spanish (mean age of first exposure, 23.2 \pm 5.1 years) and had been learning the language for a mean of $2.8 \pm 1.0$ years in the same formal context. Furthermore, none of them was exposed to the Spanish language in any context (family, professional, etc.) other than the language school at which they were receiving classes. They had, overall, a low level of proficiency in Spanish $(M=5.3 \pm$ 1.5 on a 0 -to- 10 scale, with 10 representing the highest level of proficiency; see Table 5).

Materials The materials used in Subexperiments $3 a$ and $3 b$ were the same as those in Subexperiments $1 \mathrm{a}$ and $1 \mathrm{~b}$, respectively (see Table 2).

Procedure The sequence and the timing of events were the same as those followed by Duyck and Warlop, (2009). In further detail, each trial started with the presentation of a forward mask consisting of a row of hash marks (\#) for $50 \mathrm{~ms}$ (three cycles; each cycle corresponding to $16.6 \mathrm{~ms}$ on the CRT monitor) ${ }^{4}$. Next, the prime was presented in lowercase for $50 \mathrm{~ms}$. The prime was followed by the presentation of a backward mask consisting of a row of hash marks (\#), which stayed on the screen for another $50 \mathrm{~ms}$. Finally, the target

\footnotetext{
${ }^{4}$ Please note that in the Duyck and Warlop, (2009) study, the presentation time of the forward mask, the prime, and the backward mask was of $56 \mathrm{~ms}$, whereas in the present study the duration of the masks and the primes on the screen was $50 \mathrm{~ms}$, as a result of the refresh rate specifications of the computer screens used.
} 
stimulus appeared in uppercase for a maximum of 2,500 ms or until a response was given. The rest of the procedure followed was exactly the same as that in Experiments 1a and 1b.

\section{Results and discussion}

Mean latencies for correct responses and error rates are presented in Table 6. Since the design was exactly the same as that for the previous experiments, the same analyses were performed.

\section{Experiment 3a: Spanish targets}

ANOVAs on the reaction times revealed a significant main effect of relatedness, with Spanish targets preceded by their repetitions or translations responded to $49 \mathrm{~ms}$ faster than when they were preceded by unrelated primes, $F_{1}(1,40)=$ 41.28, MSE $=2,524, p<.001 ; F_{2}(1,52)=34.28, M S E=$ $3,204, p<.001$. Furthermore, the main effect of prime language was also significant: Participants responded faster (33 ms faster) to targets preceded by Spanish primes than to targets preceded by Greek primes, $F_{1}(1,40)=18.50, M S E=$ $2,627, p<.001 ; F_{2}(1,52)=4.60, M S E=11,426, p<.05$. Finally, there was a significant interaction between Relatedness and Prime language, indicating that the identity priming effect significantly differed from the translation priming effect, $F_{1}(1,40)=8.99, M S E=1,459, p<.01$; $F_{2}(1,52)=4.39, M S E=3,018, p<.05$. In particular, participants responded $66 \mathrm{~ms}$ faster to targets when the primes were their exact repetition than when the primes were Spanish unrelated words, $F_{1}(1,40)=22.35, M S E=$ $\left.3,013, p<.001 ; F_{2}(1,52)=36.32, M S E=2,745, p<.001\right)$. Moreover, participants responded $31 \mathrm{~ms}$ faster when the primes were the non-cognate Greek translation of the targets, as compared to when the primes were Greek words that were unrelated to the targets $\left(F_{1}(1,40)=22.35, M S E=\right.$ $\left.970, p<.001 ; F_{2}(1,52)=6.73, M S E=3,477, p<.05\right)^{5}$.

ANOVAs on the error rates showed a main effect of relatedness, which approached significance only in the analysis by items, showing that participants responded more accurately ( $1.8 \%$ fewer errors) to targets preceded by related primes (either in Spanish or in Greek) than to unrelated Spanish or Greek primes, $F_{1}(1,40)=2.19, M S E=$ $58, p>.14 ; F_{2}(1,52)=3.75, M S E=43, p>.05$. No other effects were significant, all $p \mathrm{~s}>.40$.

\footnotetext{
${ }^{5}$ Just as in Experiment 1a, an additional set of analyses on the lexical decision latencies of Experiment $3 \mathrm{a}$ was conducted, removing the two perfect Spanish-English cognates (color and hotel). As was expected, the results showed that the magnitude and the level of significance of the masked translation priming effect were unaffected by the inclusion of these Spanish-English cognates in the experimental list (both $p \mathrm{~s}<.05$ ).
}

Experiment 3b: Greek targets

ANOVAs for the reaction times revealed a main effect of relatedness: Targets preceded by related primes (i.e., identical primes and translation equivalents) were responded to faster (19 $\mathrm{ms}$ faster) than wre targets preceded by unrelated primes in both languages, $F_{1}(1,40)=11.06$, $M S E=1,807, p<.01 ; F_{2}(1,52)=9.50, M S E=2,794$, $p<.01$. Furthermore, there was a main effect of prime language, which was significant only in the analysis by participants: Targets preceded by Greek primes were responded to faster (16 ms faster) than wre targets preceded by Spanish primes, $F_{1}(1,40)=7.45, M S E=1,447, p<.01$; $F_{2}(1,52)=1.29, M S E=3,709, p>.26$. Importantly, the interaction between relatedness and prime language was significant, $F_{1}(1,40)=23.51, M S E=1,331, p<.001 ; F_{2}(1$, $52)=22.83, M S E=2,578, p<.001$. Participants responded $48 \mathrm{~ms}$ faster to targets preceded by their exact repetitions in Greek, as compared with when they were preceded by unrelated Greek primes, $F_{1}(1,40)=49.13, M S E=1,031$, $p<.001 ; F_{2}(1,52)=26.68, M S E=2,770, p<.001$. In contrast, responses to targets preceded by their Spanish non-cognate translation did not differ from their responses to targets preceded by unrelated Spanish words (i.e., a nonsignificant $6 \mathrm{~ms}$ difference, both $p s>.27$ ).

ANOVAs for the error rates showed a significant main effect of prime language: Participants responded more accurately ( $1.3 \%$ fewer errors) to targets preceded by Greek primes than to targets preceded by Spanish primes, $F_{1}(1,40)=6.74, M S E=11, p<.05 ; F_{2}(1,52)=5.88$, $M S E=16, p<.05$. The rest of the effects were not significant, all $p s>.55$.

The results obtained in Experiments $3 \mathrm{a}$ and $3 \mathrm{~b}$ fully replicated those of Experiments 1a and 1b. A masked translation priming effect was found only in the forward translation direction (L1 primes and L2 targets), whereas no effect was observed in the backward translation direction (L2 primes and L1 targets). Moreover, just as in Experiments $1 \mathrm{a}$ and $1 \mathrm{~b}$, significant and equivalent bidirectional masked identity priming effects were obtained. This pattern of effects was further corroborated by a combined analysis of Experiments $3 \mathrm{a}$ and $3 \mathrm{~b}$, in which target language was included as a factor. In further detail, target language significantly interacted with relatedness in the betweenlanguage priming conditions $\left(F_{1}(1,40)=11.38, M S E=\right.$ $\left.1,307, p<.01 ; F_{2}(1,52)=6.30, M S E=3,477, p<.05\right)$, confirming the asymmetric pattern of masked translation priming effects obtained across the two translation directions. In contrast, target language did not interact with relatedness in the within-language priming conditions (both $p \mathrm{~s}>.16$ ), showing that the two repetition priming effects did not differ from each other (see Figure 1 for an overview of the critical effects of Experiments 1 and 3). 
Table 6 Mean lexical decision times (in ms, RT) and error rates (\%E) for word targets in Experiments $3 \mathrm{a}$ and $3 \mathrm{~b}$. Repetition priming was measured as the difference between the target repetition and the same language unrelated priming conditions, while translation priming was measured as the difference between the across languages repetition and across languages unrelated priming conditions

\begin{tabular}{|c|c|c|c|c|c|c|c|c|c|c|c|c|}
\hline \multirow[t]{4}{*}{ Targets } & \multicolumn{8}{|c|}{ Priming Condition } & & & & \\
\hline & \multicolumn{4}{|c|}{ Spanish (L2) } & \multicolumn{4}{|c|}{ Greek (L1) } & \multicolumn{4}{|c|}{ Priming Effect } \\
\hline & \multicolumn{2}{|c|}{ Repetition } & \multicolumn{2}{|c|}{ Unrelated } & \multicolumn{2}{|c|}{ Repetition } & \multicolumn{2}{|c|}{ Unrelated } & \multicolumn{2}{|c|}{ Repetition } & \multicolumn{2}{|c|}{ Translation } \\
\hline & $R T$ & $\% E$ & $R T$ & $\% E$ & $R T$ & $\% E$ & $R T$ & $\% E$ & $R T$ & $\% E$ & $R T$ & $\% E$ \\
\hline Spanish (L2) & 736 & 9.7 & 802 & 11.0 & 787 & 8.4 & 818 & 10.6 & 66 & 1.3 & 31 & 2.2 \\
\hline Greek (L1) & 708 & 2.9 & 702 & 2.8 & 665 & 1.3 & 713 & 1.8 & 48 & 0.5 & -6 & -0.1 \\
\hline
\end{tabular}

Note: Mean reaction time and mean error rate for nonwords were $935 \mathrm{~ms}$ and $12.1 \%$, respectively, in Experiment $3 \mathrm{a}$ and $882 \mathrm{~ms}$ and $5.4 \%$, respectively, in Experiment $3 \mathrm{~b}$

The results of Experiments $3 a$ and $3 b$ rule out the influence of the specific masked priming procedure used by Duyck and Warlop, (2009) as responsible for the bidirectional masked translation priming effects they obtained. The fact that we once more found a clearly asymmetric pattern of translation effects with a significant effect only in the L1to-L2 translation direction, even when presenting the forward mask for $50 \mathrm{~ms}$ and adding a backward mask, suggests that the reason for the discrepancy between the only two studies that have examined masked translation priming effects at low levels of L2 competence is not the additional processing time provided to the primes by the backward mask or the enhanced prime visibility due to the shortening of the exposure duration of the forward mask.

\section{General discussion}

The main finding of the present series of masked priming lexical decision experiments was a clear-cut asymmetric

Net priming effects in $\mathrm{ms}$ (unrelated - related)

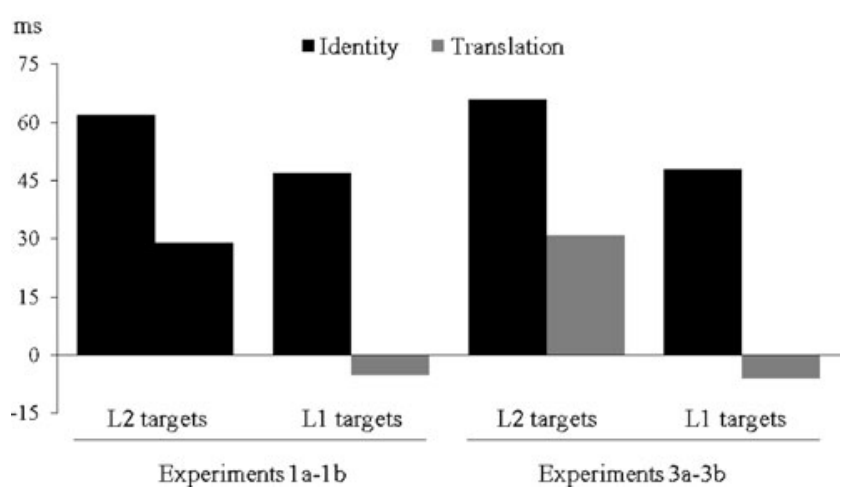

Fig. 1 Net identity and translation priming effects (unrelated-related) in milliseconds obtained in Experiments 1a and 1b and in Experiments $3 a$ and $3 b$ pattern of masked translation priming effects found in two different groups of late and low proficient Greek-Spanish bilinguals. In Experiment 1, participants responded faster to Spanish (L2) target words when they were briefly preceded by their Greek (L1) translation equivalents (Experiment 1a), as compared with when primes were unrelated Greek words (namely, a significant forward masked translation priming effect). However, participants responded equally quickly and accurately to Greek (L1) targets preceded by their Spanish (L2) translations or by unrelated Spanish words (Experiment 1b; namely, a null backward masked translation priming effect). Crucially, exactly the same asymmetric pattern of translation effects was also obtained with the same set of materials, but with a different masking sequence and timing (Experiment 3). In further detail, when the forward mask was presented for $50 \mathrm{~ms}$ and an additional 50-ms backward mask was included, a facilitative masked translation priming effect was obtained only when Spanish (L2) targets were preceded by their Greek (L1) translations, as compared with when they were preceded by unrelated Greek words (Experiment 3a). Conversely, there was no significant benefit when Greek (L1) targets were preceded by their Spanish (L2) translations, as compared with when they were preceded by unrelated Spanish words (Experiment 3b). In contrast to the translation effects, the significant within-language masked repetition priming effects that we obtained in both Experiments 1 and 3 with Greek and Spanish targets were always symmetric. Furthermore, in all the experiments, participants performed more poorly in all the between-language conditions (translation and unrelated) than in the withinlanguage conditions, showing consistent code-switching effects. The control experiment with Spanish monolingual participants who did not have any previous experience with Greek script (Experiment 2) confirmed that the Greek-toSpanish masked translation priming effects obtained with the bilingual participants were not due to uncontrolled factors, since the only significant priming effect obtained 
with these monolinguals was the within-language repetition priming effect.

Our results are totally consistent with previous masked translation priming lexical decision studies examining either both or one translation direction in bilinguals with relatively high proficiency (e.g., Gollan et al., 1997; Jiang \& Forster, 2001; Voga \& Grainger, 2007). Moreover, some of the most influential models of bilingual lexico-semantic organization have predicted that the asymmetric pattern of the masked translation priming would persist in nonfluent low proficiency bilinguals. More precisely, the forward translation priming effects obtained with both groups of Greek-Spanish bilinguals could provide support to the hypothesis proposed by the RHM that, at low levels of L2 proficiency, L2 words cannot activate the corresponding conceptual node and provide a processing advantage to their L1 translations (e.g., Kroll et al., 2002; Talamas et al., 1999). Nevertheless, our data are not conclusive as to whether translating in the L2-to-L1 direction is based only on word association, as the RHM proposes (e.g., Kroll \& Stewart, 1994; Sholl, Sankaranarayanan, \& Kroll, 1995). The null effects we obtained for L2 primes and L1 targets could initially support this hypothesis, if it is assumed that the lack of a priming effect in the lexical decision task provides evidence of the existence of weak direct connections of L2 words to their meanings. However, such a conclusion would be rather inconsistent with the fact that facilitative backward masked translation priming effects have been obtained in episodic recognition and semantic categorization tasks (e.g., Grainger \& Frenck-Mestre, 1998; Finkbeiner et al., 2004; Jiang \& Forster, 2001; Wang \& Forster, in press). Furthermore, a number of studies have shown that L2 words access concepts directly and effectively and that these lexico-semantic links are developed early in the L2 acquisition process (e.g., Altarriba \& Mathis, 1997; de Groot \& Poot, 1997; La Heij, Hooglander, Kerling, \& Van der Velden, 1996; Schoonbaert et al., 2009). Crucially, in a recent masked translation priming ERP study, Midgley et al., (2009) found that the withinlanguage repetition priming effect for L2 words involved lexico-semantic processing, since it resulted in a modulation of the N400 ERP component (i.e., more negative-going waves for unrelated L2 primes than for related L2 primes), which is typically thought to reflect lexico-semantic processing (see Kutas \& Hillyard, 1980). Consequently, the significant within-language repetition priming effects for L2 words that we found with both groups of bilinguals (e.g., salud-SALUD; Experiments 1a and 3a) could be considered as evidence supporting the hypothesis of efficient semantic processing of L2 masked primes at low levels of L2 proficiency. Nonetheless, it should be noted that this line of reasoning is based on the assumption that repetition priming effects stem mainly from higher order lexico-semantic processing, and not from lower level formal overlap between primes and targets, even though the evidence in this regard is not yet conclusive (see also Alvarez, Holcomb, \& Grainger, 2003; Jiang, 1999).

As was stated in the introduction, the persistence of the asymmetric masked translation priming effects we obtained is also predicted by some of the computationallyimplemented models of bilingual memory organization. For instance, the DevLex model (e.g., Hernandez et al., 2005; Zhao \& $\mathrm{Li}, 2006$ ) proposes that during the early stages of L2 acquisition, the associative links between L1 and L2 words are incomplete and that only L1 words are semantically defined. Although the authors of the model do not make explicit predictions regarding masked translation priming effects, this difference in the organization of L1 and L2 nodes could suggest that only L1 masked primes can effectively activate their associated meaning and, consequently, their corresponding L2 translation equivalents. However, the validity of these predictions can be tested only by implementing translation equivalents in the DevLex model and running simulations with briefly presented masked primes.

The BIA and BIA+ models also offer a good account of our results. Importantly, these are the only computational models of bilingual memory organization that have so far successfully simulated masked priming effects across different levels of L2 proficiency (e.g., Dijkstra \& van Heuven, 1998, 2002). Furthermore, the difference between the overall level of activation of L1 and L2 words they propose can perfectly explain the monodirectional masked translation priming effect we obtained. Likewise, considering the cross-script nature of our study and, therefore, that the sublexical representations of the words do not overlap, we believe that the additional sublexical feature and letter levels incorporated within the BIA/BIA+ models are required in order to account for our results. In further detail, the models propose that the larger the overlap at the feature and letter level between the words in L1 and L2, the better the L2 orthographic representations will be established. In the case of the present study, the orthographic representations of Spanish (L2) words will be less well established, since they will not receive any activation from the sublexical levels each time Greek (L1) words are encountered. Moreover, at initial stages of L2 acquisition, L2 words would have been encountered only a very limited number of times, making their orthographic representations even more unstable and their activation costlier. This idea could also account for the overall processing cost for L2 words we obtained. Finally, the activation of the sublexical levels of representation proposed by the BIA/BIA+ models (e.g., Dijkstra \& van Heuven, 2002) could also account for the significant L2-to-L2 repetition priming obtained (Experiments 1a and 3a) if one assumes that these effects 
are mainly sublexical in nature (see above). In the within-language repetition condition, primes and targets are semantically and visually identical to each other. Given the interactive activation nature of the BIA/BIA+ models, in this condition, upon prime presentation, the representations corresponding to the target would be activated throughout the sublexical, lexical and semantic levels via feed-forward connections and would, in turn, send activation to the lower levels via feedback connections, thus boosting the masked priming effects obtained in the L2-L2 repetition condition. However, following the same line of reasoning, the BIA framework would predict larger repetition priming effects for L1 items, as compared with L2 items, and especially for low proficient bilinguals, contrary to what we found (see also Gollan et al., 1997). According to the operational principles of the BIA models, such an asymmetry across the two repetition priming effects (L1 and L2) would result from the fact that feedback sent from the lexical to the sublexical levels would be stronger for L1 words than for L2 words, since the L1 lexical representations are more rapidly activated. Still, future simulations with the BIA and BIA+ models are needed in order to test the resulting pattern of within-language repetition priming effects across different levels of L2 proficiency.

To sum up, the unidirectional (L1-to-L2) masked translation priming effects found is in line with preceding evidence as well as with the predictions of most models of bilingual lexico-semantic organization. Nevertheless, these results are in clear contrast to the findings reported by Duyck and Warlop, (2009), who found a significant backward masked translation priming effect with low proficient Dutch-French bilinguals and did not replicate the typical asymmetric pattern observed between the L1-to-L2 and L2-to-L1 translation priming effects . Experiments $3 \mathrm{a}$ and $3 \mathrm{~b}$ tested whether similar bidirectional masked translation priming effects would emerge with a group of low proficient Greek-Spanish bilinguals presented with the Greek-Spanish materials used in Experiment 1 if the procedure was modified to mimic that used by Duyck and Warlop. In contrast to their findings and in line with the results of Experiment 1, we obtained a significant masked translation priming effect in the L1-to-L2 direction, whereas a null effect was found in the L2-to-L1 direction. The fact that the addition of a backward mask and the shortening of the exposure duration of the forward mask did not modulate our findings is in line with a number of previous studies showing that additional prime-processing time is not sufficient to eliminate the masked translation priming asymmetry (e.g., Finkbeiner et al., 2004; Jiang, 1999; Jiang \& Forster, 2001).
Having shown that these differences in the sequence and timing of masked priming events are not responsible for the different pattern of results obtained in the Duyck and Warlop, (2009) study and the present study, there still remain other potential reasons that should be considered. First, it should be noted that although the authors did not obtain a significant target language $\times$ prime type interaction, the $22-\mathrm{ms}$ difference in the magnitude of the two masked translation priming effects (L1 $\rightarrow \mathrm{L} 2$ and L2 $\rightarrow \mathrm{L} 1)$ cannot be easily ignored. This, in combination with the reduced number of participants (24), and the fact that a large number of experimental conditions ( 8 conditions) were included in the initial design $^{6}$, suggests that the effects may have not been symmetric and that a possible lack of statistical power in the experiment could have led to the obtained results. Furthermore, a clear difference between the two studies that could have influenced the pattern of the effects is the number of intervening scripts: Duyck and Warlop used intrascript manipulations (i.e., Roman script), whereas the present study involved a cross-script manipulation (i.e., Greek and Roman scripts). A potential role of the script manipulation on masked translation priming effects could be predicted by models assuming the existence of sublexical levels of representations, such as the BIA/BIA+ models (e.g., Dijkstra \& van Heuven, 2002). Within these frameworks, it is assumed that for within-script manipulations, every time a word in a given language is presented, activation from the sublexical levels would also spread to words in the other language, due to the shared orthographic code. Consequently, the L2 orthographic representations, as well as the interlingual links between L1 and L2 lexical representations of monoscriptal bilinguals, would be better established, since they would receive activation whenever an L1 word is encountered, via bottom-up and top-down excitatory connections between the letter level and the word level. On the contrary, under cross-script conditions, the L2 orthographic representations would be less stable and would benefit to a lesser extent from the presentation of L1 items due to their mismatching sublexical segments. Dijkstra and van Heuven stated that for biscriptal bilinguals, no effects of cross-language orthographic interactions are expected. To illustrate this point, the authors used as an example the Chinese-Latin script combination and suggested that in this case, there should be two separate sublexical orthographic stores, which will be activated in a language-specific way (Dijkstra \& van Heuven, 2002, p.183). Following this

\footnotetext{
${ }^{6}$ Duyck and Warlop, (2009) initially included a prime size manipulation, exploring masked translation priming effects for primes of different font sizes.
} 
line of reasoning, a backward masked translation priming effect, such as the one reported by Duyck and Warlop, could be obtained more easily in an intrascript manipulation, as compared with cross-script manipulations (but for proposals of a beneficial role of script change in masked translation priming, see Forster \& Jiang, 2001; Gollan et al., 1997).

It is noteworthy that significant backward masked translation priming effects have been so far reported exclusively in studies testing mono-scriptal bilinguals (Basnight-Brown \& Altarriba, 2007; Duñabeitia et al., 2010; Duyck \& Warlop, 2009; Schoonbaert et al., 2009). However, it should be also noted that there are studies that have explored monoscriptal bilinguals and have not obtained this effect (e.g., Davis, Sánchez-Casas, GarcíaAlbea, Guasch, Molero, \& Ferré, in press; Grainger \& Frenck-Mestre, 1998; Sánchez-Casas, Davis, \& GarcíaAlbea, $1992^{7}$ ). On the contrary, with the exception of the first out of five experiments reported by Jiang, (1999) with Chinese-English bilinguals, cross-script lexical decision studies have not obtained significant L2-to-L1 masked translation priming effects (e.g., Finkbeiner et al., 2004; Gollan et al., 1997; Jiang, 1999; Jiang \& Forster, 2001). Still, when biscriptal bilinguals wre asked to perform either a semantic categorization or an episodic recognition task, the otherwise elusive L2-to-L1 effect was found (e.g., Finkbeiner et al., 2004; Jiang \& Forster, 2001; Wang \& Forster, in press).

In summary, it seems feasible to assume that script variation could be a critical factor that determines the appearance of the backward masked translation priming effect in the lexical decision task. Nevertheless, any conclusion drawn in this regard should be taken with caution, since the influence of the script has not yet been examined in isolation from other confounds (e.g., L2 proficiency level or age of L2 acquisition). Current projects in our lab aim to explore this issue with several groups of bilinguals with different levels of L2 proficiency, while keeping the materials and procedures invariable across groups.

The present study provides straightforward evidence of the fact that low proficiency biscriptal bilinguals who have acquired their L2 late in life present a clear asymmetric pattern of masked translation priming effects, suggesting that some cross-lingual lexical connections

\footnotetext{
${ }^{7}$ The nonsignificant L2-to-L1 masked translation priming reported in the study by Sánchez-Casas et al., (1992) refers to unpublished lexical decision data. However, in the same study, the authors failed to find a backward masked translation priming effect in the episodic recognition task, which is in contrast to the significant backward-priming effects obtained in other studies using the same task (e.g., Finkbeiner et al., 2004; Grainger \& Frenck-Mestre, 1998; Wang \& Forster, in press).
}

are active and functional even at very early stages of L2 acquisition.

Acknowledgements Maria Dimitropoulou was the recipient of a postgraduate grant from the Government of the Canary Islands (BOC 241, 02/12/2008). This research has been partially supported by Grants SEJ200609238/PSIC, CONSOLIDER-INGENIO 2010 (CSD2008-00048) and SEMA (PSI 2009-08889) from the Spanish Ministry of Science and Innovation. The authors thank the "Society of Hispanic Studies Miguel de Cenvantes" and the "Instituto Cervantes" in Athens for their collaboration in the recruitment of participants. Thanks are also due to Eoin Sweeney for his valuable comments on an earlier draft. Finally, the authors express their gratitude to Kenneth Forster, Wouter Duyck, and an anonymous reviewer for their comments on a previous version of the manuscript.

\section{Appendix}

Word stimuli used in the experiments. Greek words are presented in bold and control primes in italic.

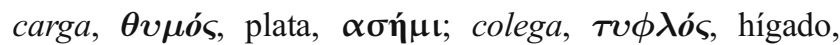

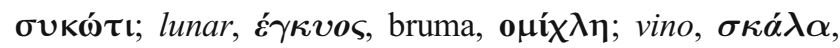

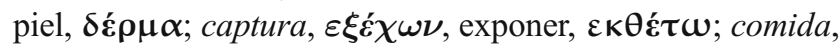

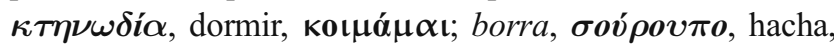

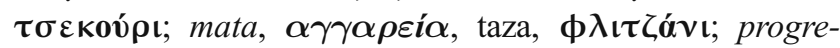
siva, $\alpha \nu \iota \sigma o \rho \rho o \pi i \alpha$, garantizar, $\delta\llcorner\alpha \beta \varepsilon \beta \alpha \iota \omega ́ v \omega ;$ atroz,

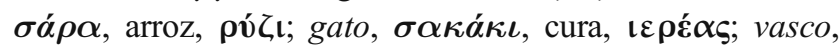

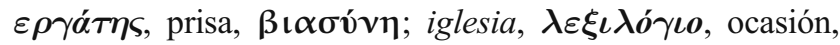

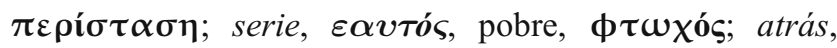

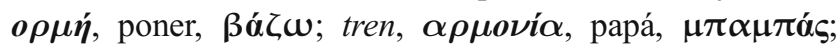

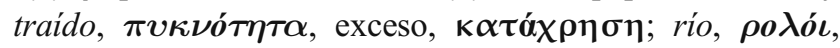

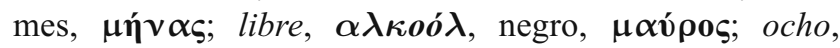

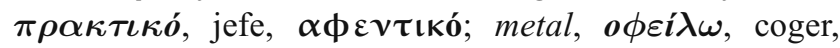

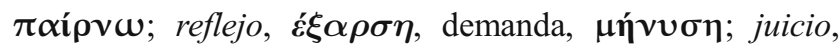

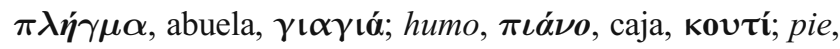

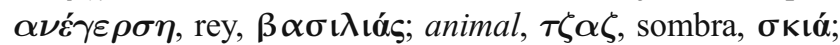

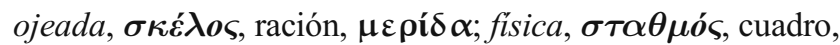

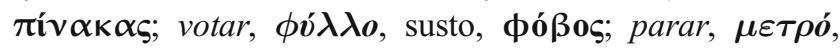

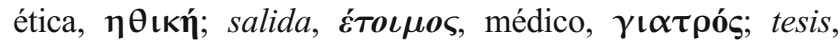

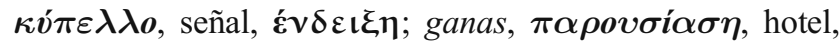

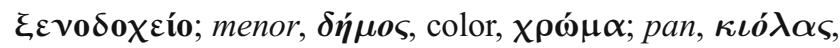

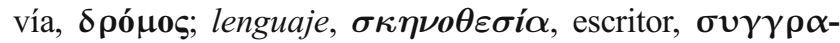

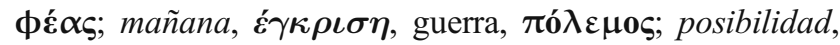
$\boldsymbol{\pi} \boldsymbol{\eta} \gamma \boldsymbol{\eta}$, naturaleza, $\boldsymbol{\phi} \boldsymbol{v} \boldsymbol{\eta}$; cita, $\boldsymbol{\sigma} \boldsymbol{\kappa} \boldsymbol{\boldsymbol { o } \rho}$, isla, $\boldsymbol{v} \boldsymbol{\eta} \boldsymbol{\sigma} \mathbf{i} ; \mathrm{mal}$,

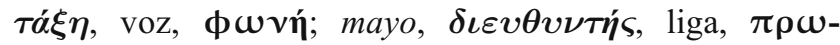

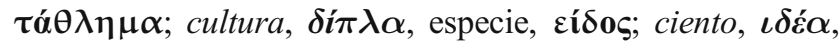

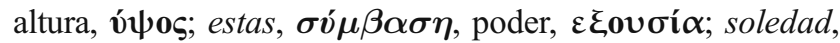

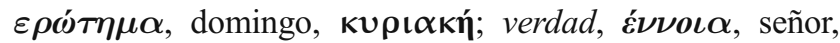
кv́

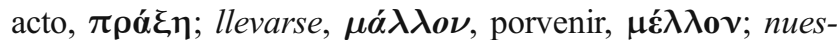

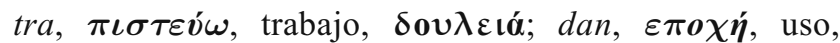

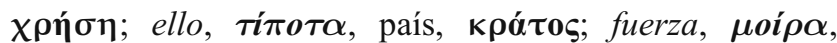

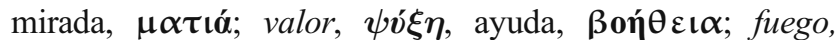

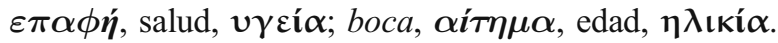




\section{References}

Altarriba, J., \& Mathis, K. M. (1997). Conceptual and lexical development in second language acquisition. Journal of Memory and Language, 36, 550-568.

Altarriba, J., \& Basnight-Brown, D. M. (2007). Methodological considerations in performing semantic and translation priming experiments across languages. Behavior Research Methods, Instruments, \& Computers, 39, 1-18.

Alvarez, R. P., Holcomb, P. J., \& Grainger, J. (2003). Accessing word meaning in two languages: An event-related brain potential study of beginning bilinguals. Brain and Language, 87, 290-304.

Basnight-Brown, D. M., \& Altarriba, J. (2007). Differences in semantic and translation priming across languages: The role of language direction and language dominance. Memory \& Cognition, 35, 953-965.

Chauncey, K., Grainger, J., \& Holcomb, P. J. (2008). Code-switching effects in bilingual word recognition: A masked priming study with ERPs. Brain and Language, 105, 161-174.

Christoffels, I. K., Firk, C., \& Schiller, N. O. (2007). Bilingual language control: An event related brain potential study. Brain Research, 1147, 192-208.

Davis, C. J., \& Perea, M. (2005). BuscaPalabras: A program for deriving orthographic and phonological neighborhood statistics and other psycholinguistic indices in Spanish. Behavior Research Methods, 37, 665-671.

Davis, C. J., Sánchez-Casas, R. M., García-Albea, J. E., Guasch, M., Molero, M., \& Ferré, P. (in press). Masked translation priming: Varying language experience and word type with SpanishEnglish bilinguals. Bilingualism: Language and Cognition.

De Groot, A. M. B., \& Nas, G. L. J. (1991). Lexical representation of cognates and non-cognates in compound bilinguals. Journal of Memory and Language, 30, 90-123.

De Groot, A. M. B., \& Poot, R. (1997). Word translation at three levels of proficiency in a second language: The ubiquitous involvement of conceptual memory. Language Learning, 47, 215-264

DelCul, A., Baillet, S., \& Dehaene, S. (2007). Brain dynamics underlying the nonlinear threshold for access to consciousness. PLoS Biology, 5, page online.

Dijkstra, A. (2007). The multilingual lexicon. In M. G. Gaskell (Ed.), Handbook of psycholinguistics (pp. 251-265). Oxford: Oxford University Press.

Dijkstra, A. F. J., \& van Heuven, W. J. B. (1998). The BIA-model and bilingual word recognition. In J. Grainger \& A. M. Jacobs (Eds.), Localist connectionist approaches to human cognition (pp. 189225). Mahwah, NJ: Erlbaum.

Dijkstra, A. F. J., van Heuven, W. J. B., \& Grainger, J. (1998). Simulating cross-language competition with the bilingual interactive activation model. Psychologica Belgica, 38, 177-196.

Dijkstra, A. F. J., \& van Heuven, W. J. B. (2002). The architecture of the bilingual word recognition system: From identification to decision. Bilingualism: Language and Cognition, 5, 175-197.

Duñabeitia, J. A., Perea, M., \& Carreiras, M. (2010a). Masked translation priming effects with highly proficient simultaneous bilinguals. Experimental Psychology, 57, 98-107.

Duñabeitia, J. A., Dimitropoulou, M., Uribe-Etxebarria, O., Laka, I., \& Carreiras, M. (2010b). Electrophysiological correlates of the masked translation priming effect with highly proficient simultaneous bilinguals. Manuscript submitted for publication.

Duyck, W., \& Brysbaert, M. (2004). Forward and backward Ttranslation in balanced and unbalanced bilinguals requires conceptual mediation: The magnitude effect in number translation. Journal of Experimental Psychology: Human Perception and Performance, 30, 889-906.
Duyck, W., \& Brysbaert, M. (2008). Semantic access in number word translation: The role of crosslingual lexical similarity. Experimental Psychology, 55, 102-112.

Duyck, W., \& Warlop, N. (2009). Translation priming between the native language and a second language: New evidence from Dutch-French bilinguals. Experimental Psychology, 56, 173179.

Finkbeiner, M., Forster, K., Nicol, J., \& Nakamura, K. (2004). The role of polysemy in masked semantic and translation priming. Journal of Memory and Language, 51, 1-22.

Forster, K. I., \& Davis, C. (1984). Repetition priming and frequency attenuation in lexical access. Journal of Experimental Psychology. Learning, Memory, and Cognition, 10, 680-698.

Forster, K. I., \& Jiang, N. (2001). The nature of the bilingual lexicon: Experiments with the masked priming paradigm. In J. L. Nicol (Ed.), One mind, two languages: Bilingual language processing (pp. 72-83). Malden, MA: Blackwell.

Forster, K. I., \& Forster, J. C. (2003). DMDX: A windows display program with millisecond accuracy. Behavior Research Methods, Instruments, \& Computers, 35, 116-124.

French, R. M. (1998). A simple recurrent network model of bilingual memory. In M. A. Gernsbacher \& S. J. Derry (Eds.), Proceedings of the twentieth annual conference of the cognitive science society (pp. 368-373). Mahwah, NJ: Erlbaum.

French, R. M., \& Jacquet, M. (2004). Understanding bilingual memory: Models and data. Trends in Cognitive Sciences, 8, 8793.

Gollan, T., Forster, K. I., \& Frost, R. (1997). Translation priming with different scripts: Masked priming with cognates and noncognates in Hebrew-English bilinguals. Journal of Experimental Psychology. Learning, Memory, and Cognition, 23, 11221139.

Grainger, J., \& Frenck-Mestre, C. (1998). masked priming by translation equivalents in proficient bilinguals. Language and Cognitive Processes, 13, 601-623.

Hernandez, A., Li, P., \& MacWhinney, B. (2005). The emergence of competing modules in bilingualism. Trends in Cognitive Sciences, 9, 220-225.

Jiang, N. (1999). Testing processing explanations for the asymmetry in masked cross-language priming. Bilingualism: Language and Cognition, 2, 59-75.

Jiang, N., \& Forster, K. I. (2001). Cross-language priming asymmetries in lexical decision and episodic recognition. Journal of Memory and Language, 44, 32-51.

Kim, J., \& Davis, C. (2003). Task effects in masked cross-script translation and phonological priming. Journal of Memory and Language, 49, 484-499.

Kinoshita, S., \& Lupker, S. (Eds.). (2003). Masked priming: The state of the art. New York: Psychology Press.

Kroll, J. F., \& Curley, J. (1988). Lexical memory in novice bilinguals: The role of concepts in retrieving second language words. In M. M. Gruneberg, P. E. Morris, \& R. N. Sykes (Eds.), Practical aspects of memory (Vol. 2, pp. 389-395). London: Wiley.

Kroll, J. F., \& Stewart, E. (1994). Category interference in translation and picture naming: Evidence for asymmetric connections between bilingual memory representations. Journal of Memory and Language, 33, 149-174.

Kroll, J. F., \& de Groot, A. M. B. (1997). Lexical and conceptual memory in the bilingual: Mapping form to meaning in two languages. In A. M. B. de Groot \& J. F. Kroll (Eds.), Tutorials in bilingualism: Psycholinguistic perspectives (pp. 169-199). Mahwah, NJ: Erlbaum.

Kroll, J. F., \& Tokowicz, N. (2001). The development of conceptual representation for words in a second language. In J. L. Nicol (Ed.), One mind, two languages: Bilingual language processing (pp. 49-71). Malden, MA: Blackwell. 
Kroll, J. F., \& Dijkstra, A. (2002). The bilingual lexicon. In R. Kaplan (Ed.), Handbook of applied linguistics (pp. 301-321). Oxford: Oxford University Press.

Kroll, J. F., \& Tokowicz, N. (2005). Models of bilingual representation and processing: Looking back and to the future. In J. F. Kroll \& A. M. B. De Groot (Eds.), Handbook of bilingualism: Psycholinguistic approaches (pp. 531-553). New York: Oxford University Press.

Kroll, J. F., Michael, E., Tokowicz, N., \& Dufour, R. (2002). The development of lexical fluency in a second language. Second Language Research, 18, 137-171.

Ktori, M., van Heuven, W. J. B., \& Pitchford, N. J. (2008). GreekLex: A lexical database of Modern Greek. Behavior Research Methods, 40, 773-783.

Kutas, M., \& Hillyard, S. A. (1980). Reading senseless sentences: Brain potentials reflect semantic incongruity. Science, 207, 203205.

La Heij, W., Hooglander, A., Kerling, R., \& Van der Velden, E. (1996). Nonverbal context effects in forward and backward word translation: Evidence for concept mediation. Journal of Memory and Language, 35, 648-665.

Léwy, N., Grosjean, F., Grosjean, L., Racine, I., \& Yersin, C. (2005). Un modèle psycholinguistique informatique de la reconnaissance des mots dans la chaîne parlée du français. Journal of French Language Studies, 15, 25-48.

Li, P., \& Farkaš, I. (2002). A self-organizing connectionist model of bilingual processing. In R. Heredia \& J. Altarriba (Eds.), Bilingual sentence processing (pp. 59-85). Amsterdam: NorthHolland.

Marian, V., Blumenfeld, H. K., \& Kaushanskaya, M. (2007). The Language Experience and Proficiency Questionnaire (LEAP-Q): Assessing language profiles in bilinguals and multilinguals. Journal of Speech, Language, and Hearing Research, 50, 940 967.

McClelland, J. L., \& Rumelhart, D. E. (1981). An interactive activation model of context effects in letter perception: Part 1 . An account of basic findings. Psychological Review, 88, 375407.

Midgley, K. J., Holcomb, P. J., \& Grainger, J. (2009). Masked repetition and translation priming in second language learners: A window on the time-course of form and meaning activation using ERPs. Psychophysiology, 46, 551-565.

Misra, M., \& Holcomb, P. J. (2003). Event-related potential indices of masked repetition priming. Psychophysiology, 40, 115-130.

Perea, M., \& Rosa, E. (2000). Repetition and form priming interact with neighborhood density at a short stimulus-onset asynchrony. Psychonomic Bulletin \& Review, 7, 668-677.
Perea, M., Duñabeitia, J. A., \& Carreiras, M. (2008). Masked associative/semantic priming effects across languages with highly proficient bilinguals. Journal of Memory and Language, 58, 916-930.

Pollatsek, A., \& Well, A. (1995). On the use of counterbalanced designs in cognitive research: A suggestion for a better and more powerful analysis. Journal of Experimental Psychology. Learning, Memory, and Cognition, 21, 785-794.

Potter, M. C., So, K.-F., Von Eckardt, B., \& Feldman, L. B. (1984). Lexical and conceptual representation in beginning and proficient bilinguals. Journal of Verbal Learning \& Verbal Behavior, 23, 23-38.

Sánchez-Casas, R. M., Davis, C. W., \& García-Albea, J. E. (1992). Bilingual lexical processing: Exploring the cognate/non-cognate distinction. European Journal of Cognitive Psychology, 4, 293 310 .

Schoonbaert, S., Duyck, W., Brysbaert, M., \& Hartsuiker, R. J. (2009). Semantic and translation priming from a first language to a second and back: Making sense of the findings. Memory \& Cognition, 37, 569-586.

Sebastián-Gallés, N., Martí, M. A., Carreiras, M., \& Cuetos, F. (2000). LEXESP: Léxico informatizado del español. Barcelona: Edicions Universitat de Barcelona.

Sholl, A., Sankaranarayanan, A., \& Kroll, J. F. (1995). Transfer between picture naming and translation: A test of asymmetries in bilingual memory. Psychological Science, 6, 45-49.

Talamas, A., Kroll, J. F., \& Dufour, R. (1999). Form related errors in second language learning: A preliminary stage in the acquisition of L2 vocabulary. Bilingualism: Language and Cognition, 2, 4558.

van Heuven, W. J. B., Dijkstra, A. F. J., \& Grainger, J. (1998). Orthographic neighborhood effects in bilingual word recognition. Journal of Memory and Language, 39, 458-483.

Voga, M., \& Grainger, J. (2007). Cognate status and cross-script translation priming. Memory \& Cognition, 35, 938-952.

Von Studnitz, R. E., \& Green, D. W. (1997). Lexical decision and language switching. International Journal of Bilingualism, 1, 3-24.

Wang, X., \& Forster, K. I. (in press). Masked translation priming with semantic categorization: Testing the sense model. Bilingualism: Language \& Cognition.

Williams, J. N. (1994). The relationship between word meanings in the first and second language: Evidence for a common, but restricted, semantic code. European Journal of Cognitive Psychology, 6, 195-220.

Zhao, X., \& Li, P. (2006). A self-organizing connectionist model of bilingual lexical development. In Proceedings of CogSci, 2006, Vancouver, Canada. 